\title{
Construction and Application of Snow-melting Runoff Model Based on MODIS Satellite Data
}

\author{
CHEN Jian, SHU Kai, WANG Jianping, LI Chunhong, WANG Feng
}

(State Grid Electric Power Research Institute/ Nanjing NARI Group Corporation, Nanjing 211000)

\begin{abstract}
It is very complicated to accurately describe the process of watershed runoff yield and concentration, which is comprehensive influenced by snow covering, temperature, precipitation, the wetland areas and other factors in the basin of Kaidu River upstream of Chahanwusu Reservoir. It is that real-time updating MODIS satellite snow cover products MOD10A2 and 30 meters by 30 meters of DEM data are applied to calculate elevation $\sim$ basin area $\sim$ snow covering area curve, virtual free reservoir is put forward to simulate the wetlands concentration of upstream Bayinbuluke and sahentuohai hydrological gauge stations and mixed melting snow and runoff yield under saturated storage concentration model is constructed in this article. The model behaved good to simulate the Inflow process of Chahanwusu Reservoir, and the relative error between simulated and measured processes reached $83.79 \%$, the deterministic coefficient reaches about 0.8 , which is better supporting Chahanwusu Reservoir's operation scheduling and dispatch decision.
\end{abstract}

\section{Introduction}

China's alpine snow cover area is widely distributed in Tibet, Xinjiang, Qinghai, Sichuan and Yunnan and other western high-altitude areas, snow cover areas are generally rare. It is difficult to deploy and maintain the equipment of the telemetry station, but at the same time, the rule of snow change with the temperature of the four seasons is obvious, which provides an important source of water for the production and life of the downstream area. It is of great significance to master the rules of melting snow in the area covered by snow and ice in the mountains, to be safely operation of the reservoir in the downstream river, flood prevention and drought control, and agricultural irrigation. Our country has four distinct seasons, it is obvious that rainfall and temperature change with the seasons. In recent years, climate change has had a greater impact on the production and flow of river basins. The influence of melting snow on the region is more significant, and it has a great value to study, analyze and forecast regional melting snow by constructing the melting runoff model.

The snowmelt runoff model can be divided into two categories, one is the conceptual model, such as Degree-day Model; One is physical models, such as Energy-balance Model.

There are many ways to determine and study the empirical degree-day factors and the coefficient of degree-day factors by integrating the factors of basin elevation, slope, slope direction, wind speed, solar radiation. Temperature is the main input of the degree-day model. Many experts and scholars have done a lot of research on the actual watershed, SRM model and SWAT model in the snow melting part of the modeling using the degree-day factor model [1]. Based on the Heihe River Basin, Li Hongyi et al. Used SRM model to simulate the runoff of the Heihe River during the snowmelt period in 2004. The simulation accuracy is good. The runoff process during the melting snow period in the source region of Urumqi River was simulated by SRM model. The results show that the Degree-day factors in different elevation zones are not constant, and the temperature and precipitation are the most sensitive factors in the model. Liu Xiaolin et al. [4] which MODIS Snow Cover is applied, Based on wind cloud geostationary satellite precipitation and GLDAS multi-source remote sensing satellite, to simulate Nian-Chu River Basin in Qinghai-Tibet Plateau with SRM model. 8-day MODIS snow cover data is used to interpolate the snowmelt coverage rate, and good application results are obtained, which provides an effective technical support for the snowmelt runoff calculation in ungauged area.

The energy balance model is based on energy conservation and mass conservation. Considering the energy transfer and change between atmosphere-water-snow cover-soil. A physical model is constructed, which needs to measure many factors, such as snow cover temperature, short wave radiation, long wave radiation, soil temperature, latent heat of evaporation, latent heat of rainfall and so on. The model of melting snow in MIKE SHE belong to energy balance model. Considering to MODIS data and T639L60 meteorological forecast field data, Qiao Peng et al. build a snow melting runoff model based on energy balance. Using the data of air humidity, wind speed and wind 
direction, solar radiation, soil temperature and humidity and soil heat flux measured by a fully automatic meteor meter as the input of the model, the snow melting runoff simulation was carried out in the Juntanghu river basin on the north slope of Tianshan Mountain, and the simulation results were satisfactory. Zhao Qiudong et al. Established the model of snow melting based on the principle of energy balance of snow cover, and calculated the parameters of snow surface net radiation, snow surface reflectance, atmospheric long wave radiation, snow surface long wave radiation, sensible heat and latent heat flux, heat storage in snow cover and soil heat flux by combining meteorological data and TERRA satellite remote sensing data. The energy balance model has a great limitation in encountering large watersheds, that is, meteorological data, heat storage in snow layers and soil heat fluxes can only be obtained by meteorological station measurements, and the temporal and spatial distribution of them in the watershed cannot be obtained at present. Because this kind of model requires a great many data, it is suitable for small scale experimental area. It is very difficult to apply this kind of model to large area natural watershed.

At present, there are several common characteristics in the research of melting snow runoff model:

Firstly, most of the areas with high-altitude mountain snow cover belong to the regions with scarce meteorological and hydrological data. MODIS and other remote sensing data are applied to be input models for both conceptual and physical models.

Second, current MODIS snow cover data can only grasp its snow cover area, and there is no way to obtain accurate snow cover thickness and density distribution information in the basin. Therefore, snow cover information generally depends on MOD10A2 (TERRA 8-day snow cover image product, $0.05 \times 0.05$ degree), according to the changes of snow cover area before and after the snow cover, the daily snow cover coverage process in the basin is calculated in the light of the changes of snow cover area before and after the snow cover. Consider the snow cover feature as a sufficient supply capacity (that is, the snow cover area fully melted over the whole period within a day, and there is not Observable that the snowfall melted completely in 0.5 days). The influence of thickness and density can be avoided by energy balance model, while the influence of thickness and density can be obscured by degree-day factor model.

Thirdly, because the meteorological conditions in the snow-covered areas on high-altitude mountains are relatively bad. Therefore the meteorological telemetry stations are not easy to build and maintain, and the parameters in these areas are usually generalized or replaced by the meteorological station data parameters in the areas with better meteorological conditions, which is one of the biggest limitations of the current snow melting runoff model. Even the data of numerical weather forecasting models, which are usually used in the ungauged watershed, they have to be initialized with the state values of the distant "adjacent stations" due to the scarcity of the stations in the process of simulation, which bring great uncertainty to the input and simulation of the runoff model of melting snow.

Fourthly, there are too many elements to measure in the energy balance model. It is not possible to set up enough weather stations to measure different elevation zones at a higher cost. At present, the popular method is to set up 1-2 automatic meteorological stations to interpolate or homogenize the spatial distribution of heat parameters in the basin.

Fifthly, the MODIS remote sensing data is used to retrieve the snow features, which cannot accurately reflect the ice characteristics of the frozen soil. In fact, the contribution of the glacier frozen soil layer to the thawing snow amount cannot be ignored because of the seasonal change of the frozen soil layer in the whole year, and the water volume model of this part cannot be accurately simulated for the time being.

At present, there are some limitations in the degree-day factor model and energy balance model respectively. In the practical application process, only through the analysis of the overall situation of the basin, we can grasp the principal contradiction and choose the appropriate model of snow melting runoff.

\section{Overview of Kaidu river basin}

The Kaidu River of Chahanwusu River Basin (hereinafter referred to as Chahanwusu Basin) originated from the south slope of Yilian Habir Ga Mountain in the middle of Tianshan Mountain. The highest peak was Keledaiwula, who's elevation is $4679 \mathrm{~m}$. The elevation of head water river is above $3600 \mathrm{~m}$, with a total area of $22000 \mathrm{~km}$ and finally flow into Bosten Lake. The whole drainage area of Qahanwusu Basin shows a U-shaped flow direction, upstream flows from east to west, passes through Bayinbuluk hydrological station and passes through a great turning point, the river changes from northwest to southeast, passing successively through hydrological stations and reservoir stations such as Savantuohe, Holguthu and Qahanwusu. There are two large alpine wetland areas above the Bayan Brook and Sajitohe hydrological stations, as shown in Figure 1 below. Due to the influence of wetlands and alpine areas, most of the upstream weather stations are located at the junction of alpine and wetlands and the weather stations are sparse and uneven. 


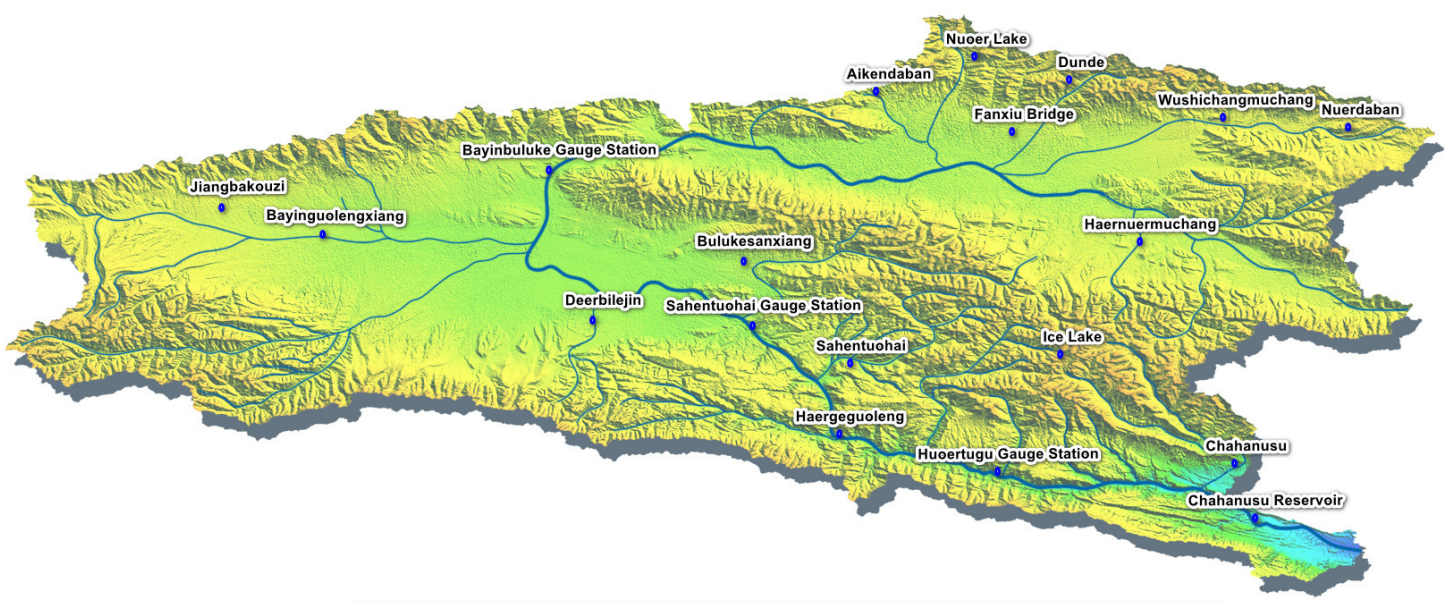

Figure 1 Station Site Distribution in the Watershed Upstream of Chahanwusu

There are two main sources of water vapor in the Chakhanusu Basin: the moist air flow from the west and the arctic air flow over the Tianshan Mountains. Especially over the Tianshan Arctic Ocean airflow, because the Kaidu River in the windward slope, easy to produce a greater precipitation. Affected by melting snow and precipitation, there are three types of floods in Chakhanusu Basin: ice-snow melting flood, rainstorm mixed with melting snow flood and rainstorm flood. The

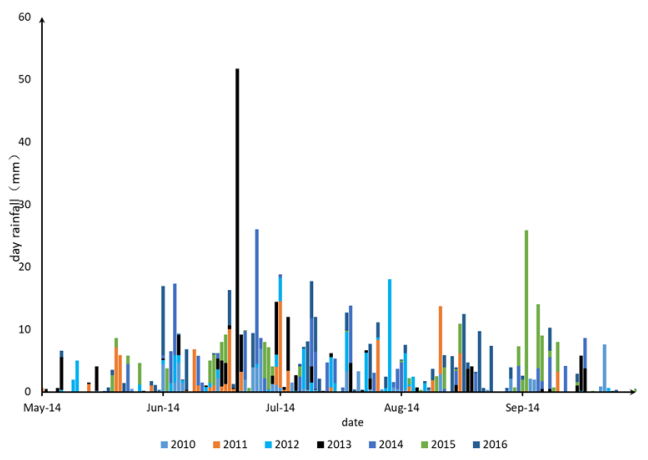

Figure 2 Comparison of Cumulative rainfall in Chahanwusu weather station over the years

From October 1 to May 1 of the following year, rainfall will rarely occur in the Chakhanusu watershed. Figure 2 shows a comparison of rainfall accumulations between May 1 and September 30 between 2010 and 2016. It shows that the main rainfall is from June to September, and the rainfall before June 1 is relatively small. However, Figure 3 shows that from late March to early April, the inflow of Chakhanusu will enter a significant period of climbing, reaching a peak between the end of April and early May, and then entering a period of decreasing flow and reaching the bottom of the valley around the end of May. According to the rainfall situation, during the two months from the last ten days of March to the last ten days of May, the runoff was mainly supplied by melting snow water from high mountains, but the snow cover area on high mountains in the Chakhanusu Basin became smaller and smaller after the beginning of May. From the end of May to the beginning of June, all the seasonal melting snowmelt was flood season of Kaidu River is concentrated between May and August. In the beginning of the flood season, the melting water of ice and snow is the main part. In June, with the increase of precipitation, the mixed flood of storm and melting snow is easy to appear. After July, the snow area of Chakhanusu Basin decreases remarkably, and the runoff of Chakhanusu Reservoir is mainly composed of precipitation and runoff.

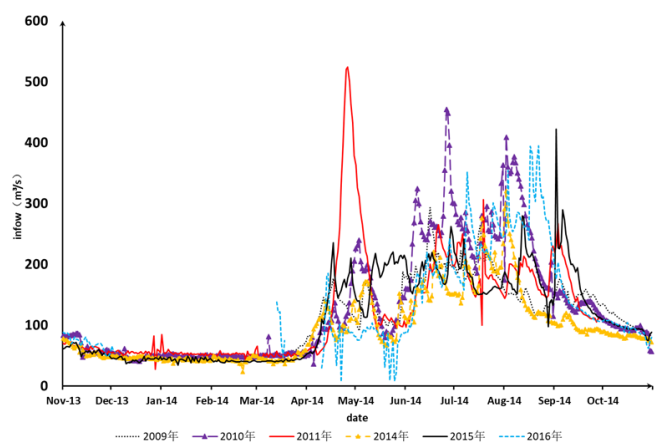

Figure 3 The comparison of the Chahanwusu Reservoir inflow flow over the years

completed, and from mid-June to mid-September, rainfall recharge runoff was dominant. After mid-September, the inflow of Chakhanusu Reservoir entered a long period of water retreat, which lasted until the end of March the following year

\section{Establishment of runoff forecasting model}

Based on the hydrological characteristics of the Chakhanusu Basin, we can divide the runoff patterns into three main stages during the year:

The first stage: from the last ten days of March to the last ten days of May: the runoff was mainly melted snow in the early stage and recharge runoff was combined with melting snow and rainfall in the later stage;

The second stage: from the first ten days of June to the middle ten days of September: recharge runoff mainly by rainfall; 
The third stage: from the last ten days of September to the middle ten days of March of the following year: the watershed enters the dry and cold period, the runoff process shows the state of returning water, mainly composed of the soil and wetland recharge water.

As shown in Figure 1 above, there are two large wetland areas above Bayinbuluke Hydrometric Station. Because of the stagnation of wetland, it has a great influence on the runoff process of Chakhanusu reservoir. The model needs to be able to simulate the storage and discharge process of natural reservoirs. Combined with the hydrological characteristics, runoff characteristics and geographic characteristics of the basin, the runoff forecast model of the Chahanwusu watershed is guided by the problems of snow melting, rainfall and wetland, and a mixed runoff and confluence model is built, which combines the process of snow melting and the virtual free reservoir ${ }^{[8]}$. The model base on MODIS satellite snow cover data to determine the snow cover area. Combined with the runoff production and confluence process of snowmelt and runoff storage, the mixed runoff production model of snowmelt is constructed. The model structure is as follows:

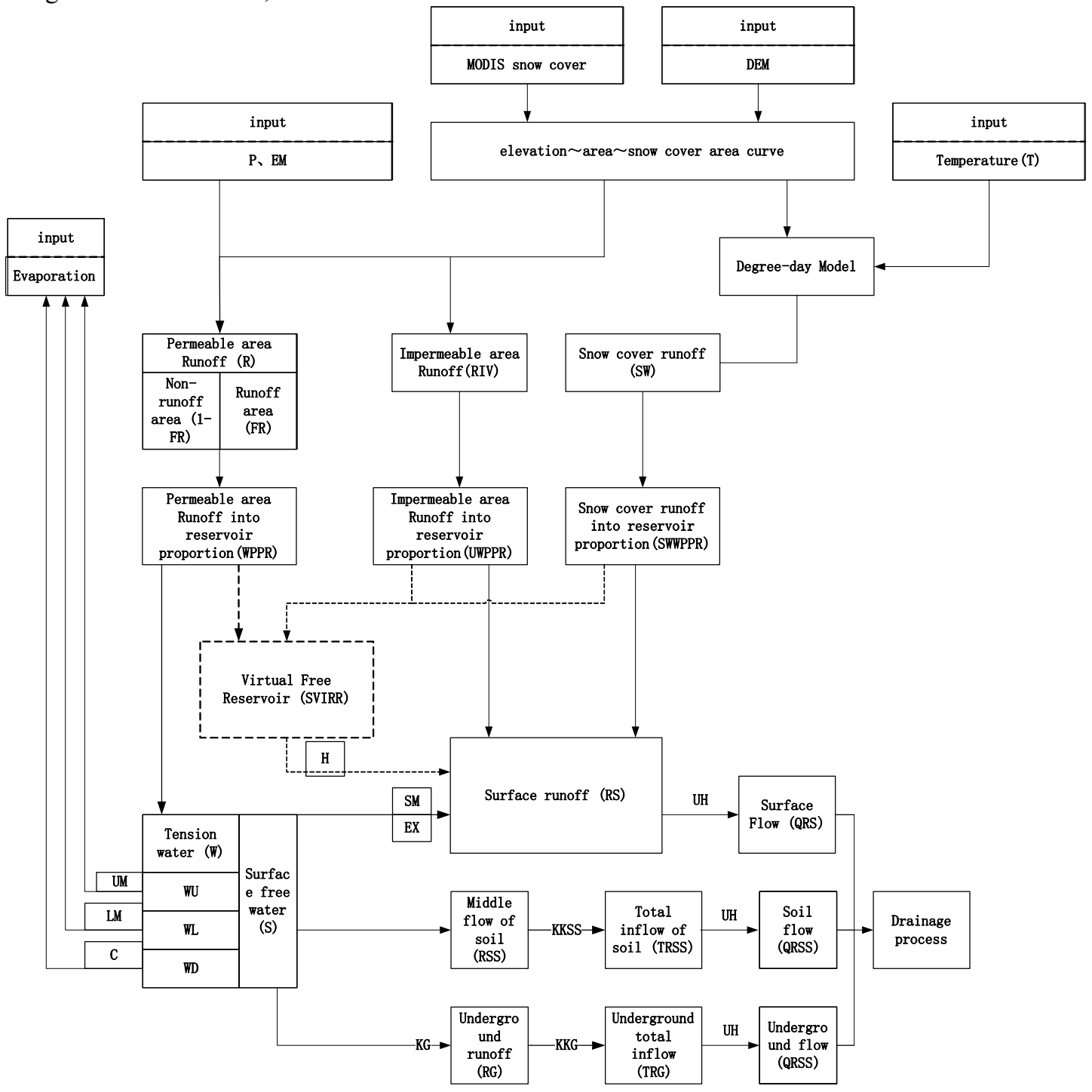

Figure 4 A Schematic Diagram of Mixed Runoff-yield Model Based on Melting Snow

Rainfall (P) : The rainfall was measured at 14 meteorological rainfall stations above the Chahanwusu Reservoir in Kaidu River.

Evapotranspiration (EM): Years of average monthly evapotranspiration data from the Kaidu River Basin.

MODIS snow cover product: MOD10A2 is used in this paper. Its resolution is $500 \mathrm{~m} \times 500 \mathrm{~m}$ and time step is 8d. Compared with MOD10A1 and MOD10A2 with the same resolution and time step of $1 \mathrm{~d}$, MOD10A2 is more accurate and reliable. Below is a download of the four areas above the Chakhanusu basin snow cover over the time change map from the following picture can be seen above the Chakhanusu basin snow cover reached the lowest value in June-August each year. From November to March of the following year, the change trend of snow cover in 2014 to 2016 is similar, and has a good periodical change rule. 

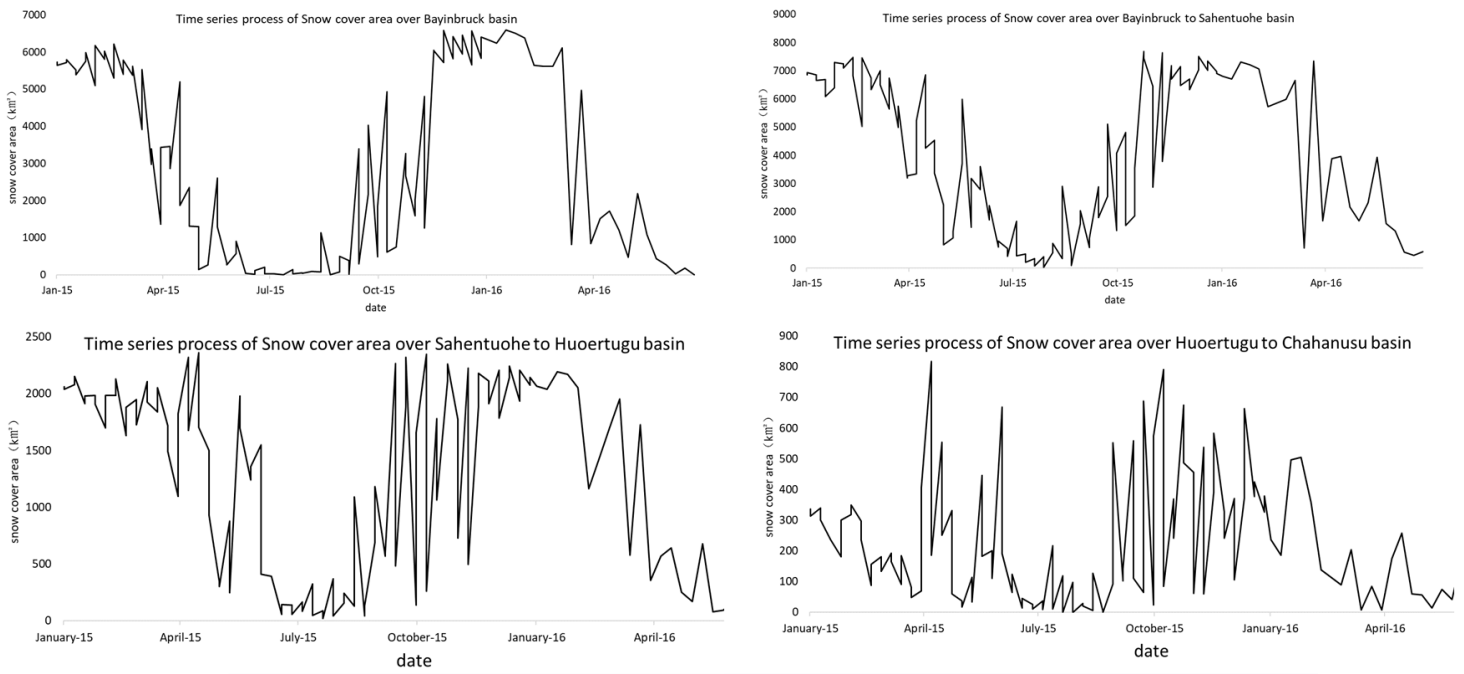

Figure 5 Variation of snow cover area over time is shown in the basin Upstream of Chahanwusu

DEM digital elevation model: DEM data with ASTER $30 \mathrm{mx} 30 \mathrm{~m}$ accuracy.

Surface air temperature (T): The surface air temperature of the basin is measured at 14 meteorological temperature stations above the Chahanwusu Reservoir in Kaidu River.

Elevation-Area-Snow Cover Curve: Using MOD10A2 of MODIS and DEM data of Kaidu River Basin, the area and snow cover distribution of each sub-basin is calculated by superimposing and analysis the MOD10A2 of MODIS and DEM data of Kaidu River Basin.

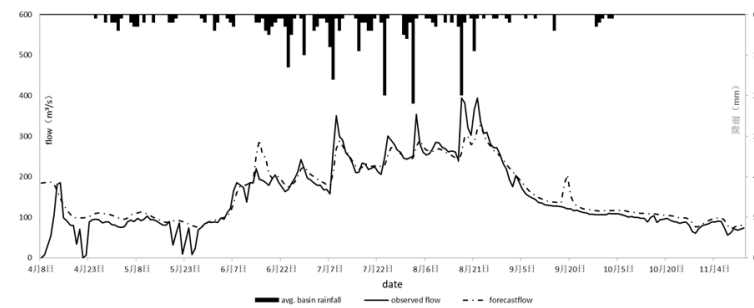

Figure 6 Comparison of the measured Inflow and the forecast Inflow processes in 2016 at Chahanwusu Reservoir

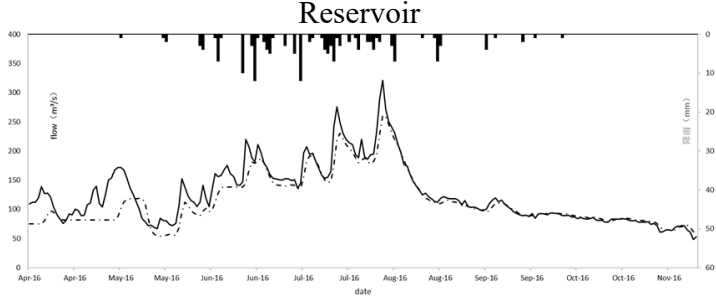

Figure 7 Comparison of the measured Inflow and the forecast Inflow processes in 2014 at Chahanwusu Reservoir

For example, table 1, the accuracy of simulation and forecasting in the above three years is as follows: the period of simulation and forecasting is from April 8 to November 28, a total of 220 days, with relative error less than $20 \%$ as the criterion, 170 days in 2016, 206 days in 2015 and 177 days in 2014. The qualified rate is $77.27 \%$, $93.64 \%$ and $80.45 \%$, respectively. The deterministic coefficients (DC) of the observed process and the forecast process are $0.823,0.814$ and 0.794 , respectively. The comprehensive qualified rate of three years is

\section{Case application}

Based on the data of hydrology, meteorology, air temperature and MODIS snow cover from 2014 to 2016 in the Chahanwusu Reservoir above the Kaidu River, a mixed runoff and confluence model combining the process of snowmelt and virtual free reservoirs is developed. The results of the model prediction simulation are as follows: Figures 6, 7 and 8 .

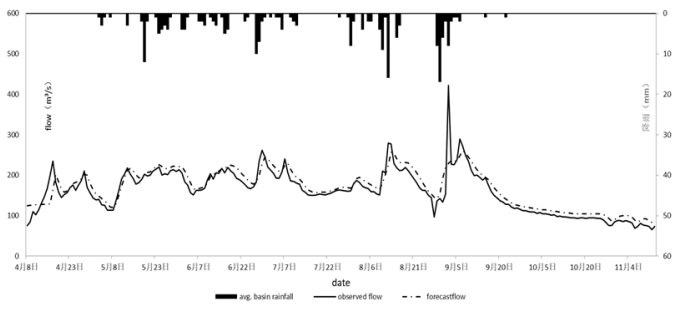

Figure 6 Comparison of the measured Inflow and the forecast Inflow processes in 2015 at Chahanwusu Reservoir

Table 1 The Simulation and Prediction Accuracy Analysis of the Chahanwusu Reservoir Inflow

\begin{tabular}{ccccc}
\hline Year & $\begin{array}{c}\text { Simulation } \\
\text { days }\end{array}$ & $\begin{array}{c}\text { Qualified } \\
\text { days }\end{array}$ & $\begin{array}{c}\text { Qualifie } \\
\text { d rate }\end{array}$ & DC \\
\hline 2016 & 220 & 170 & $77.27 \%$ & 0.823 \\
2015 & 220 & 206 & $93.64 \%$ & 0.814 \\
2014 & 220 & 177 & $80.45 \%$ & 0.794 \\
total & 660 & 553 & $83.79 \%$ & \\
\hline
\end{tabular}

$83.79 \%$, which accords with the forecasting application.

\section{Conclusions}

It is that MODIS snow cover products is used as the basis of snow cover calculation accords with the seasonal variation of snow cover. This fact reflected in the seasonal variation of snow cover in the basin shown in figure 5 above, but some snow cover rates will fluctuate more than in the previous period due to satellite 
photographs of clouds and local weather in the mountainous areas, resulting in unrealistic input of snow cover to the model simulation.

The Virtual Free Reservoir can well simulate the stagnant storage effect of wetlands on the upstream runoff of Bayinbrook and Sajituohe watershed, and better simulate the slow flow retreat process of the watershed. From the simulation results, the flow rate of Chakhanusu after September 2014 to 2016 shows a trend of returning water, and the predicted results of the model are in good agreement with that of the model.

Judging from the effect of the overall forecasting processes from 2014 to 2016, There are two results deserved to note: on the one hand, the meteorological rainfall stations in the Kaidu River Basin above Chahanwusu are relatively sparse, there are only 14 meteorological rainfall stations in the basin of more than 22000 square kilometers, and the average radiation area of each station reaches more than 1571 square kilometers; on the other hand, the meteorological rainfall stations are located in the open areas which are well maintained because of the influence of objective environmental factors such as watershed wetland and mountain elevation and so on. These two factors make the rainfall of the 14 meteorological rainfall stations is difficult to represent the average rainfall distribution of the whole basin.

The overall deterministic coefficient of the three-year simulation forecast from 2014 to 2016 is about 0.8, which indicates that the forecasting inflow is in good agreement with the actual inflow and has a high reference value for the operation and dispatch of Chakhanusu Reservoir Hydropower Station.

\section{References}

1. Zilaibu Abulaiti, Abudu Shalamu, Saydi Muattar, et al. A Review on the Application of Snowmelt Runoff Model[J]. Journal of Xinjiang University(Natural Science Edition), 2012,29(02):235-239.

2. LI Hong-yi, WANG Jian. The Snowmelt Runoff Model Applied in the Upper Heihe River Basin[J]. JOURNAL OF GIACIOIOGY AND GEOCRYOLOGY,2008,(05):769-775.

3. HUM Bao-juan, LI Zhong-qin, SUN Mei-ping, et al. Snowmelt runoff model applied in the headwaters region of Urumqi River[J]. ARID LAND GE0GRAPHY,2013,36(01):41-48.

4. Liu Xiaolin, Yang Shengtian, Zhao Changsen, et a1 . The Snowmelt Runoff Model Based on Multi-source Remote Sensing Studied and Applied in Ungauged Basins[J]. Remote Sensing Technology and Application,2015,30(4): 645-652.

5. QIAO Peng, QIN Yan, LIU Zhihui. A Spatially Distributed Snowmelt Model Based on Energy Balance $[\mathrm{J}]$ JOURNAL OF CHINA HYDROLOGY,2011,31(03):22-26+35.

6. ZHAO Qiu-dong, LIU Zhi-hui, FANG Shi-feng, et al. Improved snowmelt model based on EOS/MODIS remote sensing data[J].ARID LAND
GE0GRAPHY,2007,(06):915-920.

7. XIE Yuanyuan, ZHU Jian. Hydrological Characteristics of Kaidou River Basin[J]. J0URNAL OF CHINA HYDROLOGY,2011,31(06):92-96.

8. CHEN Jian, WANG Jianping, XIE Xiaoyan, et al. Improved XAJ Model Hydrological Forecasting Considering Human Activities Influence[J]. Water Resources and Power,2014,32(10):22-25. 